\title{
As muitas Faces do Realismo Interno de Hilary Putnam: Um Tributo
}

\author{
Léo Peruzzo Júnior ${ }^{1}$
}

\begin{abstract}
Resumo: Este artigo pretende analisar, a partir da obra de Hilary Putnam (1926-2016), algumas das muitas faces de seu realismo interno. Embora seu pensamento seja marcado pelo funcionalismo (posição parcialmente abandonada), são no externalismo e holismo semânticos que repousam suas afirmaçôeschave. Desse modo, inicialmente, reconstruímos como Putnam salvaguarda o realismo interno e sua posiçẫo pragmatista a respeito de Wittgenstein. Em seguida, mostramos como o autor sugere que o debate psicofísico entra em colapso, com base na aceitação do valor das propriedades semânticas para a instanciação do conteúdo mental.
\end{abstract}

Palavras-Chave: Realismo interno. Externalismo semântico. Holismo semântico. Funcionalismo. Hilary Putnam.

\section{INTRODUÇÁo}

A questão "como é que a linguagem se encaixa no mundo" é, no fundo, uma repetição da antiga questão "como é que a percepção se encaixa no mundo?”(PUTNAM, 2002, p. 35).

A tipografia filosófica de Hilary Putnam (1926-2016), embora marcada pelo antagonismo de suas posições, situa-se, por um lado, no limiar epistemológico do realismo interno e, por outro, no colapso metafísico da distinção entre fato e valor (PUTNAM, 1990, 2016). Nesse sentido, uma rápida digressão história em sua obra permite concluir que Putnam argumentará que a possibilidade de objetividade absoluta é, seguramente, fantasiosa e ingênua. $\mathrm{O}$ excesso e a ânsia metafísica, portanto, precisam ter suas arestas esculpidas, para que o entendimento possa inferir juízos cognitivos acerca da relação entre as nossas percepçóes e a realidade.

Ao argumentar a favor disso, Putnam é rigoroso, sugerindo que os significados não sejam objetos científicos. Essa forte conclusão, que

1 Professor do Programa de Pós-Graduação - Mestrado e Doutorado em Filosofia da Pontifícia Universidade Católica do Paraná - PUCPR - e professor do Departamento de Filosofia da FAE Centro Universitário. E-mail: leoperuzzo@hotmail.com

http://dx.doi.org/10.1590/S0101-31732017000100002 
caracterizará toda sua trajetória intelectual, encontra sua raízes no fato de que fora aluno de Rudolf Carnap (1891-1970) e Hans Reichenbah (1891-1953), antigos membros do Wiener Kreis. Talvez por essas razóes, e por uma série de outras, Putnam retome a classificação que os positivistas lógicos introduziram entre sentenças analiticas (tautologias que independem de validação exterior), sentenças sintéticas (cuja verificação e falseamento dependem de comprovação empírica) e sentenças sem valor cognitivo, ou também, contrassensos (PUTNAM, 1981, 2002), procurando introduzir o argumento segundo o qual as sentenças normalmente não possuem condiçôes de verdade independentes de seus contextos. Nesse caso, Putnam sustenta que há fatos externos e que podemos dizer como são, porém, o papel de instrumento organizador da experiência é desempenhado pelo elemento da natureza intrinsecamente social, que é a linguagem, uma vez que os fatos não são independentes de toda escolha conceitual.

Entre os primeiros críticos da conclusão anterior estão John Searle, em The Rediscovery of the Mind (1992), e Noam Chomsky, em New Horizons in the Study of Language and Mind (2000). O primeiro acusa o funcionalismo de Putnam de naturalizar o conteúdo intencional e revitalizar-se em teorias causais externalistas de referência:

A ideia por trás de tais concepções é a de que o conteúdo semântico, isto é, os significados, não podem estar inteiramente nas nossas cabeças porque o que há em nossas cabeças é insuficiente para determinar como a linguagem se relaciona com a realidade. (SEARLE, 2006, p. 75). ${ }^{2}$

Searle também dedica o capítulo 8 de Intentionality: an essay in the philosophy of mind para mostrar, ao contrário de Putnam, que os "significados estão na cabeça” e que estes não consistem em estar, por exemplo, em um estado psicológico (SEARLE, 2002, p. 275-320). J Já o gerativismo de Chomsky, munido por seus mecanismos especializados, diverge de Putnam (1998, p.

${ }^{2}$ No artigo "The analytic and the synthetic", Putnam rejeita a ideia de que definiçốes estabelecem referências. Segundo ele, a referência de um termo científico não é dada por uma definiçấo, mas por uma combinação de teorias e experimentos. Como as teorias e os experimentos dependem do ambiente externo, a referência também depende do ambiente.

${ }^{3}$ Putnam (2005, p. 292), numa entrevista concedida a Julian Baggini e Jeremy Stangroom, publicada na obra What Philosophers Think, parece atacar, implicitamente, alguns argumentos do naturalismo de Searle: "Digo que para conhecer o significado de uma palavra você tem de ver o contecto em que ela é usada, e não tanto o cérebro ou as imagens mentais de quem fala. Esse é um tipo de contextualidade. $\mathrm{O}$ holismo de significado diz que quanto mais o contexto puder reagir, melhor será a hipótese sobre o que uma palavra significa. Portanto, eles estão interligados por sua conexão mútua com a contextualidade, ao fato de que o significado de uma palava é algo que ela possui, como diz Frege, no contexto de 
15), que afirmara, em Representation and Reality, que é inconcebível supor que temos um estoque inato de noçóes. Nesse sentido, Chomsky é claramente enfático no curso de seu argumento antirrealista: "Supor que, no curso da evolução, os seres humanos passaram a ter um estoque inato de noções, incluindo carbureto e burocrata, não quer dizer que a evolução foi capaz de antecipar toda contingência física e cultural - apenas essas contingências." (CHOMSKY, 2005, p. 129).

As hipóteses de Searle e Chomsky, se analisadas a partir da perspectiva de Putnam, são triviais porque traçadas paralelamente à existência de algumas posiçôes do externalismo semântico. De certo modo, o externalismo semântico argumenta contra a dicotomia linguagem/mundo, mente/realidade, valor/fato, uma vez que só se pode falar do segundo (mundo, realidade, fato) depois de ter adotado um esquema conceitual indissociável do primeiro (linguagem, mente, valor) (PUTNAM, 1973). O colapso da verdade, portanto, é adentrar contra a ilusão de que se pode chegar aos fundamentos objetivos do mundo. Aliás, essa afirmação já é carregada de problemas, por enunciar a possibilidade de definiçóes sobre o mundo. A melhor definição de uma espécie como água, por exemplo, não muda a referência do termo. O que muda é o conhecimento sobre a espécie, pois este e a definição de um termo são insuficientes por si sós para fixar uma referência. Segundo Putnam, o fundamental é o caráter social da semântica dos termos que designam espécies naturais (PUTNAM, 2013).

\section{Do Realismo Metafísico ao Realismo InTerno: a natureza da VERDADE}

Em outras palavras, o problema retratado por Putnam é que se torna impossível realizar uma avaliação classificatória (entre sentenças analíticas ou sintéticas) para todo tipo de sentença, independentemente do contexto em que ela esteja inserida. Nesse caso, especificamente para o Positivismo Lógico, a ausência de sistematicidade na definição da sentença ou sua incongruência lógico/formal automaticamente ocasionava o nascimento de um contrassenso. É contra esse tipo de posição filosófica que Putnam centraliza sua rejeição à dicotomia fato/valor (PUTNAM, 1982).

De modo similar à questáo anterior, já no início da obra The collapse of the fact/value dichotomy and other essays, Putnam remete-se a uma pergunta clássica: "Isso é um fato ou um juízo de valor?" Substancialmente contrária

uma sentença, ou, como diz Wittgenstein em dois lugares, 'na corrente da vida', que é meu favorito princípio do contexto. Eu o chamo de princípio do contexto de Wittgenstein." 
ao que defenderá Putnam, a resposta poderia ser que os fatos são constatações objetivas e que os valores podem ser tidos como impressóes subjetivas. Entretanto, os próprios positivistas do Weiner Kreis viram-se obrigados a renunciar à tese de que os fatos devessem ser apenas observáveis diretamente pelos sentidos, porque há enunciados cognitivamente importantes, embora empiricamente não-analisáveis (PUTNAM, 2002).

Em suma, Putnam está convicto de que a dicotomia entre fato e valor entra em colapso por dois grandes motivos: o primeiro se deve ao abandono realizado por Carnap (1934) da noção de enunciados factuais como aqueles capazes de serem traduzidos pelos sentidos físicos; o segundo, sustentado pela crítica de Quine na demolição da ambivalência entre enunciados analíticos e sintéticos, isto é, náo seria possível dividir a totalidade dos enunciados de uma linguagem em verdadeiros ou falsos devido à experiência (sintéticos a posteriori) ou em enunciados necessariamente verdadeiros (analíticos a priori). Assim, de acordo com Quine (2011), qualquer enunciado, inclusive os enunciados da lógica, poderiam ser revisados pela experiência.

Em ambos os casos, Putnam, sob clara inspiração wittgensteiniana pósTractatus, acredita que os positivistas lógicos erram ao reconstruir uma visão de ciência pautada numa distinta separação entre termos valorativos e termos descritivos (PUTNAM, 2008b). Combater esse pseudo-argumento tornou-se, certamente, um dos elementos fulcrais da sua virada realista - a questão de como a linguagem se conecta com a realidade - uma vez que Putnam esteve comprometido com a visão de que a verdade é uma questão de simplesmente descobrir e afirmar o que é o caso, num mundo que existe independentemente da mente humana. Nesse sentido, Baghramian (2008, p.18) enfatiza, referindo-se a Putnam, três princípios de sua visão sobre o realismo científico que mostrariam os (pseudo)problemas derivados da relação entre as teorias cientificas (mente) e a realidade (mundo):

1) Princípio da Referência: termos utilizados em teorias científicas maduras tipicamente referem;

2) Princípio da Verdade: teorias científicas maduras são (aproximadamente) verdadeiras; e

3) Princípio da Convergência: novas teorias não substituem aquelas antigas, mas são construídas sobre elas. 
Segundo Putnam, os princípios da referência e da verdade tornam-se subsumidos ao princípio da convergência. $\mathrm{O}$ argumento para demonstrar essa posição é que, por um lado, as novas teorias descrevem (geralmente) melhor os mesmos objetos que as teorias antigas, uma vez que as primeiras contêm mais enunciados verdadeiros que estas últimas, e, por outro, porque os termos teóricos mantêm sua referência através das teorias explicando como poderia haver convergência na ciência (PUTNAM, 1978, p. 69).

O realismo cientifico, ou "realismo natural" ${ }^{4}$, deve ser visto como uma explicativa teoria empírica da prática científica, na qual o espírito deve "[...] 'transformar-se' nos seus objetos, embora apenas 'potencialmente', ou o espírito assumir a 'forma' do objeto apreendido 'sem a sua matéria'." (PUTNAM, 2002, p. 56). Essa posição, se confrontada no limiar da epistemologia tradicional, expressa, por um lado, o vazio de qualquer teoria da identidade e, por outro, os equívocos derivados da dependência do verificacionismo como modelo explicativo para compreensão do funcionamento da ciência em geral. Nesse sentido,

[a] "concepção realista natural”, que nos foi recomendada por Austin e Wittgenstein, não é, em última análise, uma "concepção metafísica alternativa”, embora, no caso de James, tivesse pretensôes de o vir a ser. Para o realismo natural, vencer é ver a inutilidade e a initeligibilidade de uma imagem que impóem uma interface entre nós próprios e o mundo. É uma forma de completar a tarefa da filosofia, aquela que John Wisdom outrora denominou uma "viagem do familiar para o familiar. (PUTNAM, 2002, p. 84).

O realismo de Putnam parece claramente negar que os instrumentos e as formas de discursos científicos sejam modos de expansão de nossas capacidades perceptuais e conceituais, ou mesmo que esses modos sejam extremamente interdependentes. Ao contrário, a "percepção" ou a "realidade" podem fundir-se numa única prática complexa, como ele mesmo procura sustentar, em O Perfil da Cognição, terceira conferência de The Threefold Cord. $\mathrm{O}$ fato de uma conjectura náo poder ser verificável, por exemplo, nem sequer em princípio, não significa que não corresponda a uma realidade. Nas pegadas de Wittgenstein, Putnam acredita que a manipulação de objetos sintáticos evita

\footnotetext{
4 "Que o sucesso da ciência em fazer muitas previsóes verdadeiras, a elaboração de melhores formas de controlar a natureza, etc., é um fato empírico indubitável. Se o realismo é uma explicação deste fato, o realismo deve ser ele mesmo uma hipótese empírica abrangente." (PUTNAM, 1978, p. 19).
} 
uma concepção deflacionista, já que não é necessário identificar a compreensão como a posse de aptidôes de verificação.

$\mathrm{Na}$ contramão de um cientificismo positivista, o realismo interno de Putnam continua sendo uma posição metafísica que vincula à epistemologia a ausência de uma distinção nítida entre sujeito/mundo, isto é, como não há uma descrição correta da realidade, a verdade é uma idealização da justificação ou, nos dizeres do autor, de aceitabilidade racional. Por um lado, o realismo interno aceita a forte intuição realista do senso comum e, por outro, é uma convergência entre o realismo metafísico, no qual a realidade é independente do sujeito e a verdade é um tipo de correspondência da linguagem com a realidade, e o relativismo conceitual.

Conforme Putnam, um não-realista ou realista interno concebe os enunciados condicionais, isto é, aqueles que versam sobre crenças sob certas condiçôes, como enunciados que entendemos apreendendo suas condiçóes de justificação (PUTNAM, 1975a, 1975b). Entretanto, isso não significa que o realismo interno abandone a distinção entre verdade e justificação, mas que a verdade pode ser apreendida como qualquer outro conceito, por meio de uma compreensão dos fatores que fazem ser racionalmente aceitável dizer que algo é verdadeiro (PUTNAM, 1981). Assim, situando-se fora do tema da dicotomia, Putnam está interessado numa espécide de realismo natural segundo o qual, na trilha de Wittgenstein, a linguagem ordinária seria suficientemente capaz de capturar a realidade. Putnam assim se refere a essa questão:

Que a ciência busque construir uma imagem de mundo que seja verdadeira é em si mesmo um enunciado verdadeiro, um enunciado verdadeiro, formal e quase vaazio; somente os critérios de aceitabilidade racional implícitos na ciência dotam de conteúdo material a seus objetivos. Em resumo, estou dizendo que a resposta a posição do oponente imaginário, aquela que define que o único objetivo da ciência é descobrir a verdade [...] é dizer que a verdade náo é a questão de fundo: a verdade mesma obtém sua vida a partir de nossos critérios de aceitabilidade racional e devemos examinar estes se desejamos descobrir os valores que estão efetivamente implícitos na ciência. (PUTNAM, 1981, p. 134).

\section{O Wittgenstein de Putnam: uma Questão aberTa?}

A postura realista de Putnam é associável ao pragmatismo americano de Pierce e Dewey, uma vez que, entre seus valores, estão o falibilismo, o pluralismo e uma postura naturalista de senso comum. E, sem dúvida alguma, 
é nesse terreno do pragmatismo que Putnam vê o desenvolvimento do pensamento wittgensteiniano e o desvelar de que a linguagem náo pode ser reduzida simplesmente ao seguimento de regras. ${ }^{5}$ Conforme aponta Putnam (2003, p.42), um dos pontos nodais das Investigaçôes Filosóficas situam-se no limiar entre aqueles que normalmente se encontram de acordo e, não menos complexo, aqueles que efetivamente estão em desacordo. A assertiva para clarear as premissas anteriores é que a singularidade interna de cada jogo de linguagem é que permite a existência de verdade, mas que não são todos que estão na capacidade de ver e reconhecê-la. Putnam quer provar que, assim como o náo cognitivista falha, ao excluir o valor da apreciação científica, o relativismo, que Wittgenstein combate, infere a verdade a partir de uma perspectiva local. Contudo, em que sentido, portanto, o realismo interno estaria condicionado ao problema da normatividade da linguagem? A resposta parece ser carregada do próprio valor da linguagem comum: os significados náo são objetos científicos, isto é, a ideia de termos de observaçâo independentes de um contexto não prova ser um meio muito sustentável.

Quando escrevi para Hilary Putnam a primeira vez, em 13 de fevereiro de 2014, o interesse era saber se ele ainda acreditava que Wittgenstein era uma "pragmatista moderado" (PUTNAM, 2015). Essa dúvida havia surgido, preliminarmente, por duas razôes: a primeira, porque estava defendendo a tese de doutoramento, na qual sustentava que, a partir dos textos de Wittgenstein, era possível derivar o que intitulava de "cognitivismo moral pragmático"; a segunda razão, um pouco mais exegética, é que acabara de ler os livros Pragmatism: An open question e The Collapse of the fact/value dichotomy and the other essays. Especialmente neste último, Putnam apresentava o realismo moral de modo que não fosse associado com a ideia de que existe algum conjunto final de verdades morais expressas em algum vocabulário moral ou legal fixo: "[...] novos conceitos trazem consigo a possibilidade de formular novas verdades. Se a ideia de uma 'verdade final' petrificada não faz sentido na ciência, é ainda mais o caso de que não faça sentido na ética e no direito.” (PUTNAM, 2008a, p. 146).

\footnotetext{
5 David Anderson (1992), em "What is Realistic about Putnam's Internal Realism", um excelente ensaio que demonstra os antaganonismos do realismo de Putnam, afirma que o mesmo poderia ser mais bem descrito como defensor de um "realismo pragmático", atribuindo a definição à herança conceitual recebida da tradição filosófica americana.
} 
Putnam enviou-me, duas semanas depois de meu contato ${ }^{6}$, o capítulo 28 de Philosophy in an Age of Science: Physics, Mathematics and Skepticism, editado por Mario De Caro e David Macarthur, que tem como título "Wittgenstein: a reappraisal". ${ }^{7}$ No referido capítulo, Putnam considera ser relevante a influência de Wittgenstein sobre seu pensamento, mas confessa que algumas seçôes da obra, especialmente os trabalhos sobre o ceticismo, foram escritas num período em que ele era menos crítico de algumas visóes do filósofo vienense. As passagens que lhe são mais caras são aquelas nas quais Wittgenstein chama a atenção para a pluralidade dos jogos de linguagem e a pluralidade de formas de vida que se entrelaçam com esses jogos.

Embora Putnam não tenha respondido explicitamente a minha pergunta, se Wittgenstein era ou não um pragmatista, no ensaio afirma concordar com Wittgenstein, ao rejeitar a ideia de que somente a linguagem científica é realmente uma linguagem de "primeira classe" para a descrição do mundo. Além disso, também aceitaria a ideia de que seguir uma regra não pode ser um processo fisicalisticamente ou, entáo, platonisticamente, uma vez que não teríamos trilhos mentais para nos assegurar claramente quando seguimos seguramente a regra em questão.

A discordância em relação a Wittgenstein residiria, segundo o próprio Putnam, na ideia de que a metafísica como um todo, iniciando-se com Sócrates, é sem valor. As interpretaçóes do Tractatus e das Investigaçôes são colocadas com o mesmo pano de fundo, o que acarretaria, por sua vez, uma série de digressóes conceituais (PUTNAM, 2003, p. 39-45). Na verdade, de acordo com Wittgenstein, a gramática metafísica é uma espécie de doença que, para ser curada, deveríamos ser submetidos a um tipo misterioso de terapia linguística. É contra esse tipo de conclusão que Putnam se manifesta absolutamente contrário e considera ser um equívoco. Assim, a visão pragmatista de Putnam claramente observa que, para Wittgenstein, a ideia segundo a qual uma palavra tem um significado que a circunda, como uma aura que acompanha todos os seus contextos de uso, determinando o modo

\footnotetext{
6 Putnam respondeu-me, para minha surpresa, da seguinte forma: "Caro Senhor Peruzzo, obrigado por sua mensagem. Estou enviando em anexo um artigo reconsiderando alguns aspectos de meu ponto de vista sobre Wittgenstein (este apareceu num livro publicado em 2012 chamado Philosophy in an Age of Science, com outros sete capítulos sobre Wittgenstein) que poderiam ser interessantes para você. Cordialmente, Hilary Putnam."

${ }^{7}$ Outros apontamentos sobre essa questáo podem ser encontrados em Naturalism in Question (2004) e Naturalism and Normativity (2010), organizados por Mario De Caro e David Macarthur.
} 
em que a usamos em todos os contextos, é uma ilusão (PUTNAM, 2003, p.38).

Voltando-nos ao conceito de filosofia e abandonando suas motivaçóes pragmatistas, é na obra Reason, Truth and History, publicada em 1981, que o autor enfrenta os problemas mais perseverantes da filosofia - a natureza da verdade, do conhecimento e da racionalidade. Todavia, é especialmente contra certo número de dicotomias, tradicionalmente preservadas como canônes pelos filósofos, que residem os limites do relativismo epistemológico, o qual seu realismo interno pretende enfrentar. Com isso, defende que há uma relação estreita entre as noçóes de verdade e racionalidade, pois o único critério para decidir o que constitui um fato é aquilo que é racional aceitar.

Uma das finalidades de seu estudo é, portanto, mostrar que nossa noção de racionalidade é, no fundo, somente uma parte de nossa concepção do desenvolvimento humano. Uma noção equivocada de racionalidade teria sido instaurada por duas importantes tendências: a primeira, o positivismo lógico, para o qual o método de justificação racional seria alcançado pela constância de uma escrita de descrição do próprio método científico; a segunda tendência, não menos grosseira, seria derivada do anarquismo científico encontrado, por exemplo, nos trabalhos de Thomas Kuhn (1922-1996) e Paul Feyerebend (1924-1994). Segundo esses autores, a ciência não teria uma justificação racional, porque segue os saltos gestálticos que as diferentes épocas produzem. Essa visão relativista e antagônica seria responsável pelo florescimento dos diferentes paradigmas de racionalidade.

Assim, contra essa imagem de racionalidade, Putnam adverte que a verdade depende de valores, visto que, embora não haja nenhum conjunto de princípios morais, a-históricos, isso não significa aceitar que tudo seja simplesmente cultural e relativo (PUTNAM, 1981). Isso significa, pois, que a aceitabilidade racional, por exemplo, nas ciências exatas, depende de virtudes cognitivas, como a "coerência" e a "simplicidade funcional", evidenciando que ao menos alguns conceitos de valor representam propriedades das coisas a que elas se aplicam. Não pertencem, nesse caso, precisamente aos sentimentos da pessoa que os usa. Tomando esses argumentos como verdadeiros, pois, a teoria de Putnam sugere que o impacto da ciência na concepção de racionalidade nos obriga a não aceitar que esta última deva ser definida como observação pura ou inferência neutra, a partir de premissas de valor neutro. As teorias científicas são verdadeiras e, portanto, não neutras, porque carregam uma percepção da realidade da qual nossa mente náo pode ser dissociada. Concordando parcialmente com 
Rorty (1991), Putnam afirma que "[...] não faz sentido comparar, por um lado, os meus pensamentos e crenças e, por outro, as coisas 'tais como elas são em si mesmas", mas discorda de que "[...] essa ideia sejam uma pressuposição necessária da concepção comumde que há objetos que não são partes do pensamento ou da linguagem, ou da concepção igualmente comum de que o que dizemos sobre esses objetos algumas vezes capta bem os fatos." (PUTNAM, 2008, p. 135-136).

\section{O COLAPSO DO PROBLEMA MENTE/CORPO}

Putnam dedicou grande parte de seus ensaios, livros e conferências à dissolução do problema mente/cérebro. Argumentou que o computador digital seria uma interessante analogia para explicar a relação mente/cérebro: a mente seria correspondente ao software e o cérebro, ao hardware. Os estados mentais seriam definidos em termos de seu papel funcional e teriam uma realidade abstrata, seguindo a descrição atribuída a um software. É difícil medir, sob o ponto de vista epistemológico, a extensão ou o abandono do funcionalismo, em sua filosofia. Entretanto, seu astucioso exemplo do cérebro numa cuba tem despertado uma série de posiçóes que ainda podem suscitar um diálogo inacabado, se considerarmos sua posiçáo realista na ciência (LEVINE, 1993). Assim Putnam (1981, p. 28-29) escreve:

Eis uma possibilidade de ficçáo científica discutida pelos filósofos: imagine-se que um ser humano (pode imaginar que é você mesmo) foi sujeito a uma operação por um cientista perverso. O cérebro da pessoa (o seu cérebro) foi removido do corpo e colocado numa cuba de nutrientes que o mantém vivo. Os terminais nervosos foram ligados a um supercomputador científico que faz com que a pessoa de quem é o cérebro tenha a ilusão de que tudo está perfeitamente normal. Parece haver pessoas, objectos, o céu, etc.; mas realmente tudo o que a pessoa, (você) está experienciando é o resultado de impulsos electrónicos deslocando-se do computador para os terminais nervosos. $\mathrm{O}$ computador é tão esperto que se a pessoa tenta levantar a mão, a retroacção do computador fará com que ela "veja" e "sinta" a máo sendo levantada. Mais ainda, variando o programa, o cientista perverso pode fazer com que a vítima "experiencie" (ou se alucine com) qualquer situação ou ambiente que ele deseje. Ele pode também apagar a memória com que o cérebro opera, de modo que à própria vítima lhe parecerá ter estado sempre neste ambiente. Pode mesmo parecer à vítima que ela está sentada e a ler estas mesmas palavras sobre a divertida mas completamente absurda suposição de que há um cientista perverso que remove os cérebros das pessoas dos seus corpos e os coloca numa cuba de nutrientes que os mantém vivos. Os 
terminais nervosos é suposto estarem ligados a um supercomputador científico que faz com que a pessoa de quem é o cérebro tenha a ilusão de que...

Quando este tipo de possibilidade é mencionado numa conferência sobre teoria do conhecimento, o propósito, evidentemente, é levantar de uma maneira moderna o clássico problema do cepticismo relativamente ao mundo exterior. ( Como é que você sabe que não está nesta difícil situação?) Mas esta situação difícil é também um dispositivo útil para levantar questóes sobre a relação mente/mundo.

Em vez de ter apenas um cérebro na cuba, podíamos imaginar que todos os seres humanos (talvez todos os seres sencientes) são cérebros numa cuba (ou sistemas nervosos numa cuba no caso de alguns seres apenas com um sistema nervoso mínimo considerado já como "senciente"). Naturalmente, o cientista perverso teria que estar de fora - estaria? Talvez não haja nenhum cientista perverso, talvez (embora isto seja absurdo) aconteça simplesmente que o universo consista num mecanismo automático cuidando de uma cuba cheia de cérebros e sistemas nervosos.

Agora suponhamos que o mecanismo automático está programado para nos transmitir uma alucinaçáo colectiva, em vez de uma quantidade de alucinaçóes individuais não relacionadas. Assim, quando me parece estar a falar consigo, a si parece-rque você não tem ouvidos (reais), nem eu tenho uma boca e língua reais. Antes, quando eu produzo as minhas palavras, o que acontece é que os impulsos eferentes deslocam-se do meu cérebro para o computador, que ocasiona que eu "ouça" a minha própria voz pronunciando essas palavras e "sinta" a minha língua mover-se, etc., e que você "ouça” as minhas palavras, me "veja" a falar, etc. Neste caso, estamos, num certo sentido, realmente em comunicação. Não estou enganado sobre a sua existência real (apenas sobre a existência do seu corpo e do "mundo externo" fora dos cérebros). De um certo ponto de vista, nem sequer importa que "o mundo inteiro" seja uma alucinação colectiva; porque, afinal, você ouve realmente as minhas palavras quando eu falo consigo, mesmo que o mecanismo não seja o que supomos que ele é. (Evidentemente, se fôssemos dois amantes fazendo amor, em vez de apenas duas pessoas levando a cabo uma conversa, então a sugestão de que se tratava apenas de dois cérebros numa cuba podia ser perturbadora.)

Quero agora pôr uma questão que parecerá muito tola e óbvia (pelo menos para algumas pessoas, incluindo alguns filósofos muito sofisticados), mas que nos levará a autênticas profundezas filosóficas bastante rapidamente. Suponha-se que toda esta história era de facto verdadeira. Poderíamos nós, se fôssemos assim cérebros numa cuba, dizer ou pensar que o éramos?

O experimento mental do cérebro numa cuba pretende mostrar que não só o corpo é desnecessário para a experiência e a cognição, como também 
ele pode ser substituindo por um software rodando adequadamente num hardware. Contudo, que tipo de argumento poderia ser oferecido a tais pessoas que, nesse mundo imaginário descrito anteriormente, acreditam ser cérebros numa cuba? Putnam responde da seguinte forma: "Mesmo que estas pessoas possam pensar e "dizer" qualquer palavra que nós pensamos ou dizemos, não podem "referir-se" ao que nós nos referimos. Em particular, não podem dizer ou pensar que são cérebros numa cuba." (PUTNAM, 1981, p. 21).

Putnam também é conhecido, especialmente na filosofia da mente, pela formulaçáo clássica do que se denominou Externalismo Semântico. Para que isso fosse possível, suas críticas dirigiram-se principalmente ao "solipsismo metodológico", segundo o qual o conhecimento do significado de uma palavra e o conteúdo de nossos estados mentais seriam determinados exclusivamente por situaçóes cerebrais. ${ }^{8}$ Assim, o experimento do cérebro numa cuba procura atacar a versão de que os estados mentais corresponderiam a eventos mentais sem nenhuma relação com os fatores ambientais ou sociais.

O externalismo semântico sustenta o argumento de que nosso conhecimento do significado não é determinado apenas pelos eventos neuronais. Ao contrário, os fatores externos seriam responsáveis, necessariamente, pela instanciação do conteúdo mental. E, para tal, os conteúdos mentais, primeiramente, são identificados a partir de frases cuja natureza é pública e, posteriormente, tornam-se propriedades semânticas. Dito de outra maneira, as propriedades semânticas são transferidas ao conteúdo mental formando, de acordo com Putnam, o que se chama popularmente de "consciência" ou "mente". A percepçáo, portanto, não poderia ser ignorada, como escreve o autor, em The Threefold Cord:

A questão "como é que a linguagem se encaixa no mundo?" é, no fundo, uma repetição da antiga questão "como é que a percepção se encaixa no mundo?”. E será de admirar se, depois de trinta anos em que se ignorou virtualmente a tarefa iniciada por um punhado dos meus heróis na área de filosofia - a de desafiarem o ponto de vista da percepção que se tem adotado desde o século XVII - a própria ideia de que o pensamento e a linguagem se relacionam, de fato, com a realidade, tenha começado a parecer cada vez mais problemática? Será de admirar-se que não consiga ver como é que o pensamento e a linguagem se encaixam no mundo, se nunca se menciona a percepção? (PUTNAM, 2002, p. 35).

8 Uma crítica à posição de Putnam pode ser encontrada em McDowell, 1992. 
As propriedades semânticas desses conteúdos, a que Putnam se refere, não são obtidas de forma solipsista, mas por agentes cognitivos, uma vez que a totalidade do debate corpo/mente é desajustada, por insistir numa imagem psicofísica. Desse modo, o que Putnam tem rejeitado "[...] não é a 'tese' de correlação psicofísica, mas a ideia de que a questão faça sentido." (PUTNAM, 2002 , p. 222). As características psicológicas são, portanto, individuadas de formas sensíveis ao contexto, envolvendo fatores externos, sociais e projeçóes que consideramos ser algo natural ou não fazê-las. Putnam pretende, por fim, salvaguardar o ponto de vista tradicional segundo o qual (mesmo que nossos estados psicológicos sejam individuados de forma externa) há outros estados que são adequadamente internos como num "teatro interior". O autor acredita que, dessa forma, palavras, imagens mentais e outros signos não estáo ligados àquilo que pretendem representar ou que intrinsencamente os representam, porque a intenção é condição necessária à existência de representação.

\section{CONSIDERAÇÓES FinaIS}

Do externalismo semântico ao realismo interno, Putnam compreende que a verdade, diferentemente do modo como foi tratada pela epistemologia tradicional, está estreitamente ligada à racionalidade e à história. Como consequência desse argumento se pode derivar que a racionalidade se associa diretamente com as concepçóes e métodos históricos que se desenvolvem ao longo da história. Nesse sentido, Putnam afirma que a "[...] aceitabilidade e a relevância são interdependentes em qualquer contexto. $\mathrm{O}$ uso de qualquer palavra - seja esta 'bom', 'consciente', 'vermelho' ou 'magnético' - supóem uma história, uma tradição de observação, generalização, prática e teoria.” (PUTNAM, 1988, p. 200). É dentro dos próprios limites da racionalidade que se pode afirmar que os "critérios racionais" são opostos à existência de normas imutáveis e eternas.

Conforme Putnam, especialmente em Reason, Truth and History, há sempre relaçóes subjacentes que devem ser consideradas, quando tratamos a resposta para a pergunta "O que é a verdade?" Com isso, ao formular um ambiente filosófico que reconcilie aspectos da teoria da correspondência e do realismo metafísico, Putnam não pensa o mundo como a totalidade permanente de objetos independentes da mente. Ao contrário, o que existe é somente uma descrição completa do "modo como o mundo é", no qual o conceito de verdade envolve uma relação não-dicotômica entre as palavras e 
as coisas externas. É nesse universo epistemológico que Putnam sugere que se deve aceitar como racional a possibilidade de existência de diversas descriçóes de verdade, uma vez que a linguagem não permite apenas descrever o mundo, mas questioná-lo e completá-lo com nossas percepções, concepções e opiniões.

Fundamentalmente, o que Putnam procura mostrar é que, do mesmo modo que o não-cognitivista falha, ao excluir o valor da apreciação científica, o relativismo contemporâneo infere a noção de "verdade" a partir de uma perspectiva local. Em outras palavras, a obra de Putnam encontra-se a meio caminho entre a metafísica e um tipo particular de relativismo pragmático, no qual as hipóteses acerca da pergunta "Será a verdade objetiva possivel?" repousam sobre a arquitetura da concepção de justificação racional. Para tanto, segundo Putnam, por um lado, a filosofia não é uma coleção de "problemas" que podem ser "resolvidos", mas "um grande empreendimento humanístico e científico" (PUTNAM, 2015); e, por outro, a justificação racional da ciência (ou do conhecimento em geral) deve estar amparada "[...] de forma democrática, cooperativa e falível" (PUTNAM, 2008a) e pelas práticas do permanente diálogo, como afirma, no último parágrafo de Reason, Truth and History:

Tem este diálogo um fim ideal? Há uma concepção verdadeira de racionalidade, uma moralidade verdadeira mesmo quando tudo aquilo que temos são nossas concepçôes destas? Neste último ponto, as opinióes dos filósofos, como aquelas de todos os demais, se dividem. Richard Rorty, em seu discurso presidencial na American Philosophical Association, optou com firmeza pelo ponto de vista de que somente existe o diálogo; não pode postular-se nenhum fim ideal, nem tampouco seria necessário. Contudo, a afirmação de que "somente existe o diálogo" difere em algo do relativismo que se autorrefuta, discutido no capítulo 5 ? O mesmo fato de que falemos de nossas diferentes concepçóes como diferentes concepçóes de racionalidade postula uma Grenz-begriff, um conceito limite de verdade ideal. (PUTNAM, 1988, p. 213).

JÚNIOR, Léo Peruzzo. The many faces of Putnam's internal realism: a tribute. Tans/form/ ação, Marília, v. 40, n. 1, p. 9-24, Jan./Mar., 2017.

ABSTRACT: This article analyzes the many faces of Hilary Putnam's (1926-2016) internal realism. Although his thinking is marked by functionalism (a position he partially abandoned), it is in externalism and semantic holism that his key statements rest. Initially, we reconstruct how Putnam's thinking safeguards internal realism and a pragmatic position with respect to Wittgenstein. We then show how the author suggests that the psychophysical debate collapses after the acceptance of the value of semantic proprieties for the instantiation of mental content. 
KeYwords: Internal Realism; Semantic Externalism; Semantic Holism; Functionalism; Hilary Putnam.

\section{REFERÊNCIAS}

ANDERSON, D. L. What is realistic about Putnam's internal realism? Philosophical Topics, v. 20, n. 1, p.49-83, Spring 1992.

BAGGINI, J.; STANGROOM, J. What philosophers think. London; New York: Continuum, 2003.

BAGHRAMIAN, M. From realism back to realism: Putnam's long journey. Philosophical Topics, v. 36, n. 1, p. 17-35, 2008.

. Hilary Putnam (1926-2016). Philosophy Now, n. 114, jun/jul.2016.

CARNAP, R. The unity of science. London: Kegan Paul; Hubner, 1934.

CHOMSKY, N. Novos horizontes no estudo da linguagem e da mente. São Paulo: Editora da UNESP, 2005.

DE CARO, M.; MACARTHUR, D. Naturalism in question. Cambridge: Harvard University Press, 2004.

. Naturalism and normativity. New York: Columbia University Press, 2010.

LEVINE, J. Putnam, Davidson and the seventeenth-century picture of mind and world. International Journal of Philosophy Studies, v.1, n. 2, p. 193-230, 1993.

McDOWELL, J. Putnam on mind and meaning. Philosophical Topics, v. 20, n. 1, p. 3548, 1992.

PUTNAM, H. Meaning and reference. The Journal of Philosophy, v. 70, n. 19, p. 699-711, 1973.

. Mind, language, and reality. Cambridge: Cambridge University Press, 1975a.

. Mathematics, matter and method. Cambridge: Cambridge University Press, 1975b.

. Beyond the fact-value dichotomy. Critica: Revista Hispanoamericana de Filosofia, v. 14, n. 41, p. 3-12, ago. 1982.

. Razón, verdad e história. Madrid: Tecnos, 1988.

. Realism with a human face. Cambridge: Cambridge University Press, 1990.

. A tripla corda: mente, corpo e mundo. Lisboa: Instituto Piaget, 2002.

. Il pragmatismo: una questione aperta. Roma: Laterza, 2003.

. O Colapso da verdade e outros ensaios. Aparecida, SP: Ideias \& Letras, 2008a.

. Wittgenstein and realism. International Journal of Philosophy Studies, v. 16, n. 1,

p. 3-16, 2008b. 
. The development of externalist semantics. Theoria, v.79, n. 3, p. 192-203, 2013. . Mind, Body and World in the Philosophy of Hilary Putnam [Interview]. Trans/ Form/Ação, v. 38, n. 2, p. 211-216, 2015.

. Realism. Philosophy \& Social Criticism, v. 42, n. 2, p. 117-131, 2016.

QUINE, W. De um ponto de vista lógico. São Paulo: Editora da UNESP, 2011.

RORTY, R. Objectivity, relativism and truth: philosophical papers. Cambridge: Cambridge University Press, 1991.

SEARLE, J. Intencionalidade. São Paulo: Martins Fontes, 2002. . A redescoberta da mente. São Paulo: Martins Fontes, 2006.

Recebido em 10/11/2016

Aceito em 15/01/2017 